\title{
Laryngoscope brightness determined by visual inspection and during mannequin laryngoscopy
}

\author{
Gaurav Arora, BSc · Paul A. Brousseau, BEd, RRT • \\ Andrew D. Milne, MD, MSc, BEng, FRCPC
}

Received: 1 November 2017/Revised: 22 June 2018/Accepted: 25 June 2018/Published online: 31 July 2018

(c) Canadian Anesthesiologists' Society 2018

\section{To the Editor,}

Adequate light intensity is crucial for visualization during laryngoscopy. This can be problematic as light intensity of laryngoscope blades deteriorates with repeated use and cleaning. ${ }^{1}$ Typically, laryngoscope function is checked by simple visual assessment of blade light brightness prior to induction. While the Canadian Guidelines to the Practice of Anesthesia stipulate that laryngoscopes must be checked prior to use, they do not specify a method. ${ }^{2}$ The aim of this present study was to compare the adequacy of laryngoscope blade light brightness, as perceived by simple visual inspection, with the adequacy of illumination during direct laryngoscopy performed on a mannequin.

After institutional research ethics board approval (CDHA-RS2014-074, July 2013), a convenience sample of 35 anesthesia staff and residents $(\mathrm{n}=25$ and 10, respectively) provided written informed consent to participate. A laryngoscope brightness testing chamber ${ }^{3}$ was employed to identify ten used laryngoscope blades with light intensities ranging from approximately 140-

Presented in part at the Canadian Anesthesia Society Annual Meeting, Ottawa, Ontario, Canada, June 2015. (Amended data.)

G. Arora, BSc - A. D. Milne, MD, MSc, BEng, FRCPC

Department of Anesthesia, Pain Management, and Perioperative Medicine, Dalhousie University, Halifax, NS, Canada

P. A. Brousseau, BEd, RRT

Department of Anesthesia, QEII Health Centre, Halifax, NS, Canada

A. D. Milne, MD, MSc, BEng, FRCPC ( $\varangle)$

School of Biomedical Engineering, Dalhousie University,

Halifax, NS, Canada

e-mail: admilne@dal.ca
2,200 lux (Table). This range encompasses previously proposed minimum light intensity requirements for laryngoscopy. ${ }^{3-5}$ Ten baseline illumination measurements were obtained for each blade using a single new 3.5 volt rechargeable handle fitted with a xenon bulb (Heine, Herrsching, Germany) prior to assessment by study participants. Participants were blinded to the measured brightness intensity of each blade.

Each participant was given the ten laryngoscope blades in random order (computer generated random number sequence) and asked to visually assess the blades for their brightness as they would do during their routine preinduction check. The rating of the blade brightness was recorded as either "acceptable" or "unacceptable". After completing visual inspection of all ten blades, the participant was then asked to assess the light intensity of the blades (acceptable/unacceptable) during laryngoscopy on a mannequin (Laerdal, Stavanger, Norway). As before, the order of blade testing was randomized. The mean ambient room lighting for all testing sessions was $406 \pm 84$ lux (1 standard deviation). The laryngoscope handle was recharged for ten minutes after each participant's assessment and the brightness of each blade was rechecked after each test to ensure no inadvertent changes in light intensity.

The proportion of participants rating each blade as "acceptable" was calculated along with the 95\% confidence interval (CI). Blade acceptance was compared using the Fisher exact test and Bonferroni correction. Acceptability of blade brightness during visual inspection vs mannequin laryngoscopy was analyzed for each individual blade. The proportion of participants accepting a given blade compared with the brightest blade (blade \# 10) was also analyzed for both visual inspection and mannequin laryngoscopy. ${ }^{4}$ Given our sample size, we 
Table Blade brightness and illumination acceptability

\begin{tabular}{|c|c|c|c|c|c|c|c|c|}
\hline \multicolumn{2}{|l|}{ Blade data } & \multicolumn{3}{|c|}{ Visual inspection } & \multicolumn{3}{|c|}{ Mannequin laryngoscopy } & \multirow{2}{*}{$\begin{array}{l}P \text { value } \\
\text { visual } v s \\
\text { mannequin }^{\mathrm{a}}\end{array}$} \\
\hline Number/size & $\begin{array}{l}\text { Light } \\
\text { intensity } \\
\text { (lux) }\end{array}$ & $\begin{array}{l}\text { Number } \\
\text { accepting } \\
\text { blade }\end{array}$ & $\begin{array}{l}\text { Proportion } \\
\text { accepting blade and } \\
95 \% \text { CI }\end{array}$ & $\begin{array}{l}P \text { value in } \\
\text { comparison to } \\
\text { blade } 10^{\mathrm{b}}\end{array}$ & $\begin{array}{l}\text { Number } \\
\text { accepting } \\
\text { blade }\end{array}$ & $\begin{array}{l}\text { Proportion } \\
\text { accepting blade and } \\
95 \% \text { CI }\end{array}$ & $\begin{array}{l}P \text { value in } \\
\text { comparison to } \\
\text { blade } 10^{\mathrm{b}}\end{array}$ & \\
\hline $1-\mathrm{MAC} 4$ & $141(21)$ & $9 / 35$ & $0.257(0.093-0.492)$ & $<0.001 *$ & $4 / 35$ & $0.114(0.019-0.324)$ & $<0.001 *$ & 0.28 \\
\hline $2-\mathrm{MAC} 4$ & $259(49)$ & $23 / 35$ & $0.657(0.420-0.848)$ & $<0.001 *$ & $19 / 35$ & $0.543(0.313-0.760)$ & $<0.001^{*}$ & 0.47 \\
\hline $3-\mathrm{MAC} 3$ & $352(71)$ & $22 / 35$ & $0.629(0.392-0.827)$ & $<0.001^{*}$ & $19 / 35$ & $0.543(0.313-0.760)$ & $<0.001 *$ & 0.63 \\
\hline $4-\mathrm{MAC} 4$ & $420(71)$ & $30 / 35$ & $0.857(0.639-0.969)$ & 0.054 & $27 / 35$ & $0.771(0.539-0.924)$ & $0.005^{*}$ & 0.54 \\
\hline 5 - MAC4 & $674(93)$ & $34 / 35$ & $0.971(0.800-1.0)$ & $\dagger$ & $32 / 35$ & $0.914(0.714-0.991)$ & 0.239 & 0.61 \\
\hline $6-\mathrm{MAC} 4$ & $729(99)$ & $33 / 35$ & $0.942(0.754-0.997)$ & 0.493 & $32 / 35$ & $0.914(0.714-0.991)$ & 0.239 & 1.0 \\
\hline 7 - MAC3 & $841(180)$ & $34 / 35$ & $0.971(0.800-1.0)$ & $\dagger$ & $34 / 35$ & $0.971(0.800-1.0)$ & $\dagger$ & $\dagger$ \\
\hline $8-$ MAC3 & $1088(163)$ & $35 / 35$ & $1.0(0.871-1.0)$ & $\dagger$ & $35 / 35$ & $1.0(0.871-1.0)$ & $\dagger$ & $\dagger$ \\
\hline 9 - MAC3 & $1937(366)$ & $35 / 35$ & $1.0(0.871-1.0)$ & $\dagger$ & $35 / 35$ & $1.0(0.871-1.0)$ & $\dagger$ & $\dagger$ \\
\hline 10 - МAC3 & $2260(382)$ & $35 / 35$ & $1.0(0.871-1.0)$ & Reference & $35 / 35$ & $1.0(0.871-1.0)$ & Reference & $\dagger$ \\
\hline
\end{tabular}

Laryngoscope blade size (Macintosh \# 3 or 4), and the mean light intensity (standard deviation) measured prior to adequacy assessment. The number and proportion of participants that deemed each blade to be "acceptable" during initial visual inspection and subsequent mannequin laryngoscopy are shown with the corresponding Bonferroni-adjusted Clopper-Pearson 95\% confidence intervals (CI). The Fisher exact test was used for comparisons of acceptability by visual inspection $v$ s mannequin laryngoscopy for each individual blade ${ }^{\mathrm{a}}$ and for comparison with Blade \# $10^{\mathrm{b}}$. Based on a Bonferroni correction for multiple comparisons, a level of $P<0.05 / 6(P<0.008)$ was considered significant for visual inspection $v s$ mannequin laryngoscopy. For comparison to blade \# 10, a significance level of $P<0.05 / 5(P<0.01)$ was used for visual inspection and $P<0.05 / 6(P<0.008)$ was used for mannequin laryngoscopy.* Several blades had insufficient variance in acceptability rating to calculate a $P$ value between proportions. ${ }^{\dagger}$

made no attempt to perform subgroup analyses that considered a confounding effect of the training level (staff/resident).

Overall, there was no significant difference observed between the proportion of staff accepting a given blade during visual inspection and mannequin laryngoscopy (Table). Blades with less than 420 lux had lower acceptability compared with the brightest blade during visual inspection, whereas during mannequin laryngoscopy, blades producing less than 674 lux had lower acceptability compared with the brightest blade.

The minimum brightness at which 0.99 of participants considered blade brightness to be "acceptable" was $674 \pm$ 93 lux for visual inspection and mannequin laryngoscopy based on the upper $95 \%$ CI for each group. This is considerably greater than the 500 lux recommended by the ISO ${ }^{5}$ but comparable to 700 lux proposed by Baker. ${ }^{4} \mathrm{We}$ recommend regular quality audits of reusable laryngoscopes blades using a light meter $^{3}$ to ensure that they are sufficiently bright.

Conflicts of interest None declared.
Editorial responsibility This submission was handled by $\mathrm{Dr}$. Steven Backman, Associate Editor, Canadian Journal of Anesthesia.

Funding This research did not receive any specific grant from funding agencies in the public, commercial, or not-for-profit sectors.

\section{References}

1. Nishiyama T. Changes in the light intensity of the fiberoptic laryngoscope blade by steam sterilization. Anesth Analg 2007; 104: 908-10.

2. Dobson G, Chong M, Chow L, et al. Guidelines to the practice of anesthesia - revised edition 2018. Can J Anesth 2018; 65: 76-104.

3. Milne AD, Brousseau PA, Brousseau CA. Effects of laryngoscope handle light source on the light intensity from disposable laryngoscope blades. Anaesthesia 2014; 69: 1331-6.

4. Baker PA, Raos AS, Thompson JM, Jacobs RJ. Visual acuity during direct laryngoscopy at different illuminance levels. Anesth Analg 2013; 116: 343-50.

5. International Organization for Standardization. ISO 7376-2009: Anesthetic and Respiratory Equipment. Laryngoscopes for Tracheal intubation. Available from URL: https://www.iso.org/ standard/44073.html (accessed July 2018). 